C.B. Казанский, канд. техн. наук, доц. ORCID 0000-0002-6113-2600

В.И. Моссаковський, ассист. ORCID 0000-0002-5096-5957

P.A. Меркотан, магистр ORCID 0000-0002-4813-9656

Национальный технический университет Украины «Киевский политехнический институт имени Игоря Сикорского» ИССЛЕДОВАНИЕ КОЛЕБАНИЙ ПРОВОДОВ ВОЗДУШНЫХ ЛИНИЙ ЭЛЕКТРОПЕРЕДАЧИ С УЧЕТОМ ГОЛОЛЕДНО-ВЕТРОВЫХ НАГРУЗОК

Статья посвящена проблеме повышения надежности воздушных линий электропередачи, расположенных в районах с высокой вероятностью возникновения повышенных ветровых и гололедных загрузок. В статье показана необходимость повышения эксплуатационной надежности воздушных линий электропередачи как одного из основных элементов системы передачи электрической энергии. Рассмотрен вопрос совершенствования построения модели колебаний проводов воздушных линий электропередачи в различных режимах ветровых и гололедных загрузок.

Представлена последовательность моделирования процесса обтекания провода марки АC 70/11 потоком воздуха без учета и с учетом образования гололеда различной формы. Приведены результаты моделирования, которые подтверждают иелесообразность учета силь и направления ветрового потока, а также формы гололеда, которые являются определяющими факторами при определении амплитуды и частоты колебаний. Показано, что использование результатов моделирования позволит существенно повысить эксплуатационную надежность воздушных линий электропередачи, особенно напряжением от 6 до 35 кB, расположенных в районах со значительными гололедно-ветровыми нагрузками.

Обоснована ичелесообразность дополнительных исследований возникновения сложных колебаний проводов с разной частотой и амплитудой, которые возникают в случае образования гололеда, форма которого не является идеально ицлиндрической и существенно влияет на изменение колебательного процесса. Такими исследованиями, в частности, может быть пространственное моделирование колебательного процесса провода в пролете линии электропередачи с учетом гололедных образований различной формы.

Ключевые слова: воздушные линии электропередачи, колебания проводов, гололедно-ветровые нагрузки, динамическое моделирование

Надійшла 22.02.2018

Received 22.02.2018

УДК 621.18.063

A.B. Баранюк, канд. техн. наук, ст. препод., ORCID 0000-0001-6008-6465

A.M. Терех, канд. техн. наук, с. н. с., ORCID 0000-0002-1320-8594

B.А. Янушевский, магистрант, ORCID 0000-0003-0179-1433

Национальный технический университет Украины «Киевский политехнический институт имени Игоря Сикорского»

\title{
СFD-МОДЕЛИРОВАНИЕ АЭРОДИНАМИЧЕСКОГО СОПРОТИВЛЕНИЯ ПУЧКОВ ВИНТООБРАЗНЫХ ТРУБ
}

Средствами CFD-моделирования проведено исследование аэродинамического сопротивления шахматных пучков винтообразных труб с равноразвитой поверхностью в диапазоне изменения чисел Рейнольдса от $9,5 \cdot 10^{3}$ до $45 \cdot 10^{3}$. Изучены модели пучков с отношениями шагов между трубами $s_{1} / s_{2}=0,46$, 0,92 и 1,83 . Показано, что аэродинамическое сопротивление пучка винтообразных труб с $s_{1} / s_{2}=0,92$ всего на 5\% выше аналогичного гладкотрубного пучка. Предложены расчетные соотношения для определения аэродинамического сопротивления исследованных шахматных пучков однозаходных винтообразных труб с равноразвитой поверхностью. Выявлено, что коэффициент $C_{\mathrm{s}}$ и показатель степени $n$ при числе Рейнольдса в уравнении подобия зависят от шаговых характеристик пучков. Использование винтообразных труб в теплообменниках типа «газ-газ» позволяет увеличить интенсивность теплообмена на (10-30\%) при умеренном росте аэродинамического сопротивления, в результате чего можно существенно улучшить массогабаритные характеристики теплообменных аппаратов.

Ключевые слова: винтообразная труба, равноразвитая поверхность, шахматный пучок, аэродинамическое сопротивление, расчет

(C) А.В. Баранюк, А.М. Терех, В.А. Янушевский, 2018 
На сегодняшний день известно, что существующие теплообменные поверхности, которые изготовлены из гладких круглых труб, исчерпали свои возможности с точки зрения увеличения их теплоаэродинамической эффективности. Поэтому поиск новых форм теплообменных поверхностей, которые способны обеспечить высокую интенсивность теплообмена при минимальной затрате энергии на прокачку теплоносителей, является актуальной задачей.

Одним из рациональных способов увеличения теплоаэродинамических характеристик поверхностей нагрева, например для теплообменных устройств типа „газ-газ”, является одновременное развитие внешней и внутренней поверхностей труб [1-6]. В работах [1-6] показано, что форма конструкции таких труб позволяет одновременно существенно увеличить как внешнюю, так и внутреннюю поверхность теплообмена в $(1,15-1,4)$ раза. Винтообразные выступы-впадины (рис.1), которые чередуются с определенным шагом, вызывают дополнительную турбулизацию пограничного слоя [5]. За счет закручивания внутреннего и внешнего потоков и резкого изменения скорости потока при омывании поверхности происходит одновременное увеличение интенсивности внутреннего и внешнего теплообмена в зависимости от геометрических характеристик труб и шагов между ними соответственно в 1,5-2,5 и 1,11,3 раза. За счет этого коэффициент теплопередачи увеличивается на $25-70 \%$ по сравнению с пучками труб круглого сечения.

Такие трубы способны изготавливать специалисты ММИ КПИ им. Игоря Сикорского [7], которые разработали технологию получения винтовых профилей на круглых трубах. Профилирование выполняется роликами двух обкатывающих головок - одно- и трех роликовой за один проход. Усовершенствованная технология получения винтообразных труб позволяет изготавливать трубы малого диаметра (меньше 20 мм) с однозаходным винтообразным профилем большой длины (больше 1 м).

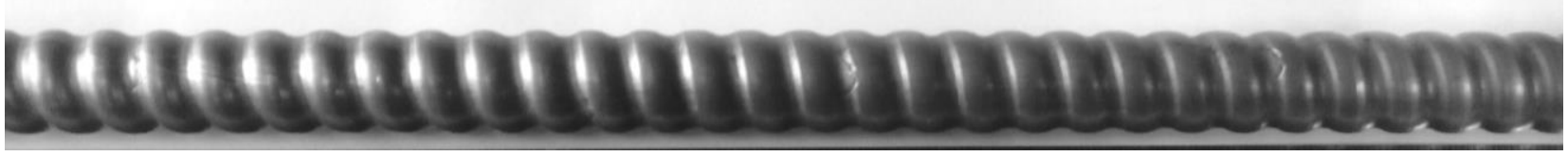

Рисунок 1 - Фотография длинномерной винтообразной трубы диаметром 16 мм и шагом между выступами 8мм.

Для возможного применения винтообразных труб в качестве теплообменных поверхностей, необходимо при помощи численного и экспериментального методов провести исследования аэродинамического сопротивления шахматных пучков таких труб, получить расчетные соотношения для определения коэффициентов сопротивления в условиях внешнего их омывания, а также провести сравнение полученных данных с данными для шахматных пучков круглых труб.

Материал данной статьи посвящен исследованию аэродинамического сопротивления шахматных пучков винтообразных труб, определению соотношений для расчета аэродинамического сопротивления пучков таких труб в условиях внешнего поперечного омывания воздушным потоком средствами CFD (Computation Fluid Dynamics) моделирования.

\section{Методика исследований}

Исследование аэродинамического сопротивления выполнено для трех типов винтообразных труб, которые отличаются шагом винтовой линии $-t=8$ мм, 12 мм и 20 мм. При этом, высота выступов-впадин винтовой линии $h$ оставалась величиной постоянной и равной 2,5 мм. Определение аэродинамического сопротивления шахматных пучков винтообразных труб выполнялась с помощью CFD-моделирования для трех компоновок шахматных пучков с шаговыми параметрами $s_{1} / s_{2}=22 / 48=0,46, s_{1} / s_{2}=22 / 24=0,92$ и $s_{1} / s_{2}=44 / 24=1,83$. Значения поперечных $s_{1}$ и продольных $s_{2}$ шагов исследованных пучков, а также основные геометрические размеры труб приведены на рис. 2 и 3 . Количество рядов труб в шахматном пучке поперек и вдоль потока составляло соответственно $z_{l}=10$ и $z_{2}=9$. 


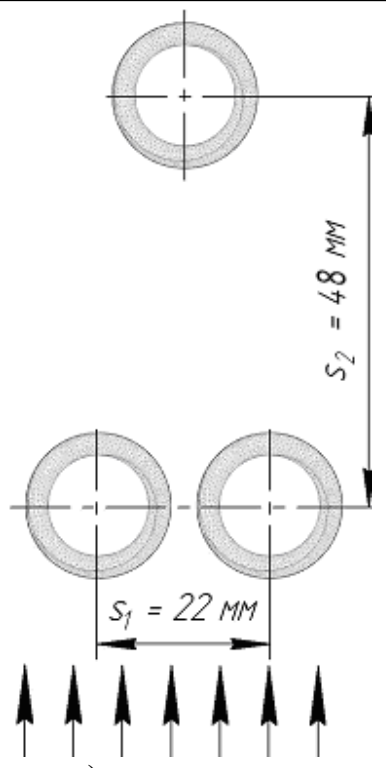

a)

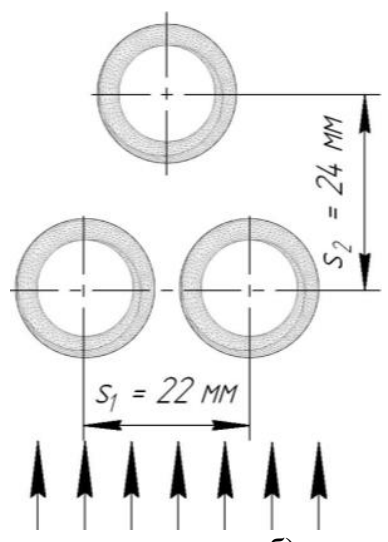

б)

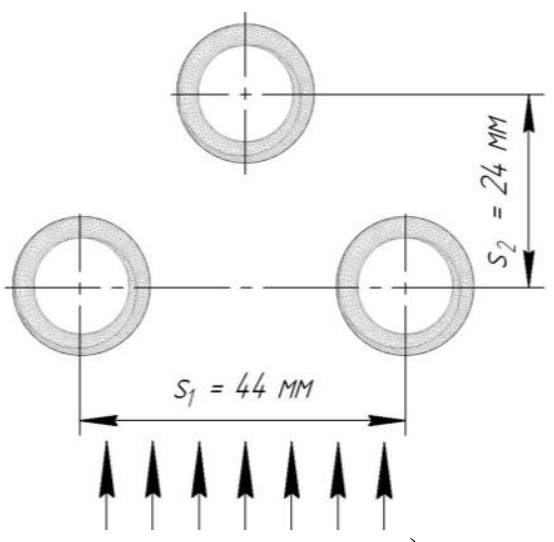

B)

Рисунок 2 - Исследованные пучки винтообразных труб с $s_{1} / s_{2}=0,46$ (а), $s_{1} / s_{2}=0,92$ (б) и $s_{1} / s_{2}=1,83$ (B).

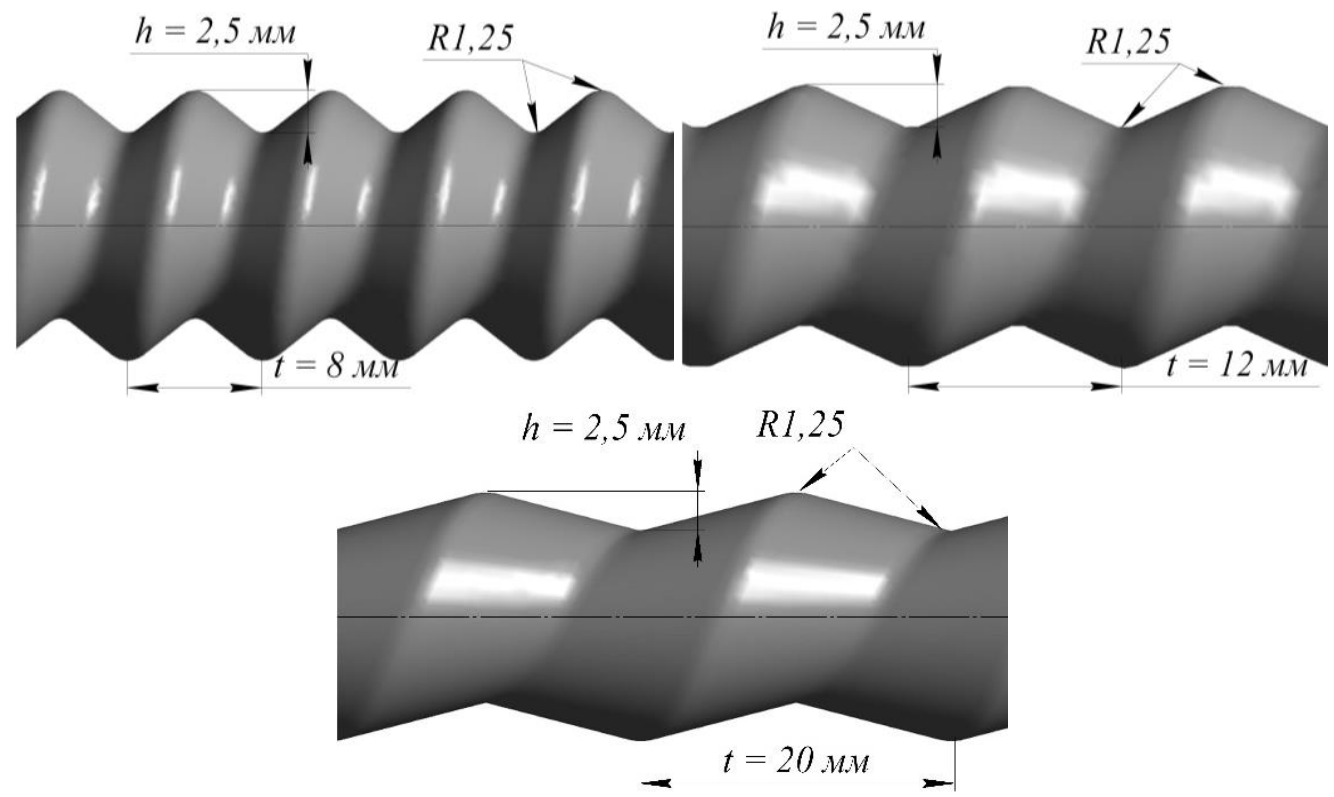

Рисунок 3 - Геометрические параметры исследованных винтообразных труб.

Трехмерная расчетная сетка для случая омывания потоком внешней поверхности винтообразных труб представлена на рис. 4. Количество ячеек необходимых для дискретизации потока в межтрубном пространстве не превышало 4 млн. Как свидетельствует рис. 4, конечно-элементная сетка межтрубного пространства двухслойная и содержит пристеночную область, которая аппроксимируется с помощью элементарных параллелепипедов и межтрубную область, которая аппроксимируется с помощью тетраэдров. Такое построение расчетной сетки выполнено согласно рекомендациям [8] и обеспечивает максимальную достоверность полученных результатов с физической точки зрения.

Вычисления на моделях проводились при периодических граничных условиях, которые определялись в боковых плоскостях. Расстояние между упомянутыми боковыми плоскостями отвечало поперечному шагу между трубами $s_{1}$ (рис.2).

Приведенный ниже анализ выполнялся с помощью разработанных конечно элементных CFDмоделей винтообразных труб в среде программного комплекса ANSYS-Fluent. Задача решалась в стационарной постановке с соблюдением требования достижения независимости решения от плотности расчетной сетки. При моделировании для всех типоразмеров выбирались неизменными следующие граничные условия: 
- $\quad$ температура потока на входе в пучок винтообразных труб $t_{\varepsilon x}=26^{\circ} \mathrm{C}$;

- $\quad$ температура стенки трубы $t_{c m}=100^{\circ} \mathrm{C}$.

- $\quad$ расход воздуха на входе в пучек $G=1 \cdot 10^{-4} \mathrm{\kappa r} / \mathrm{c}, 9 \cdot 10^{-4} \mathrm{\kappa r} / \mathrm{c}, 9 \cdot 10^{-3} \mathrm{\kappa r} / \mathrm{c}, 3 \cdot 10^{-2} \mathrm{\kappa r} / \mathrm{c}$.

Теплофизические свойства воздуха задавались в виде полиномиальных функций температуры.

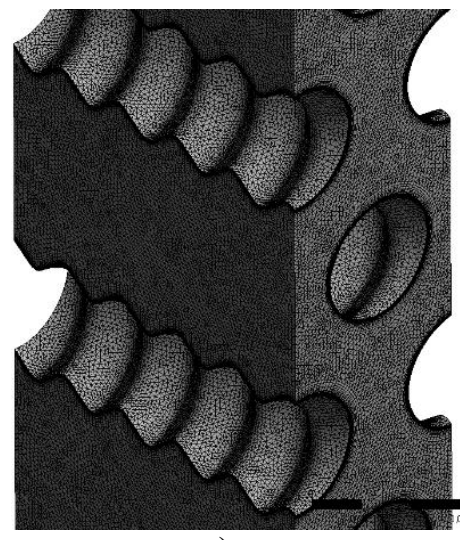

a)

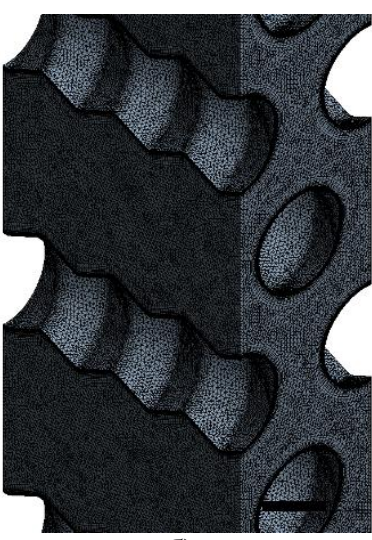

б)

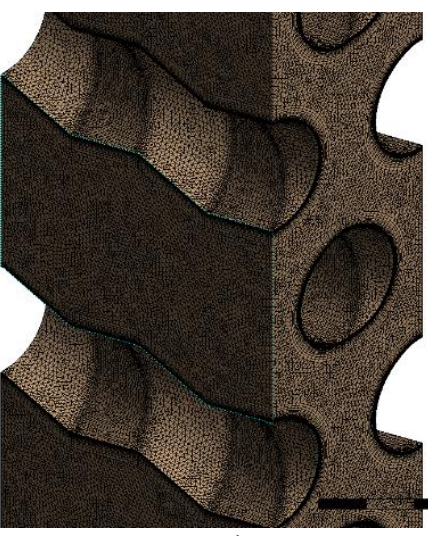

B)

Рисунок 4 - Расчетная конечно-элементная сетка модели пучка из $s_{1} / s_{2}=0,92$, которая состоит из винтообразных труб, отличающаяся шагом винтовой линии $t=8$ мм (а), 12 мм (б) и 20 мм (в)

Аэродинамическое сопротивление $\Delta P$ исследованных пучков винтообразных труб определялось как разница абсолютных давлений между входом и выходом потока из пучка труб. Упомянутые абсолютные давления определялись с помощью команды Report программы ANSYS-Fluent. По значениям $\Delta P$ определялись числа Эйлера для всего пучка в целом

$$
\mathrm{Eu}=\Delta P / \rho w_{\varkappa}^{2},
$$

и числа Эйлера, отнесенные к одному поперечному ряду

$$
\mathrm{Eu}_{0}=\mathrm{Eu} / z_{2}
$$

Результаты экспериментов описывались зависимостями вида $\lg \left(\operatorname{Eu}_{0}\right)=f(\lg (\operatorname{Re}))$, где числа Рейнольдса рассчитывались по внешнему диаметру трубы $D$. Значение расчетной скорости потока, которая входят в выражение чисел Эйлера $\mathrm{Eu}$ и чисел Рейнольдса $\mathrm{Re}$ определялись в минимальном проходном сечении пучка.

\section{Моделирование аэродинамического сопротивления пучков винтообразных труб}

На рис. 5 приведены в виде зависимостей $\mathrm{Eu}_{0}=f\left(\mathrm{Re}_{\mathrm{D}}\right)$ результаты расчета аэродинамического сопротивления для трех компоновок шахматных пучков винтообразных труб $\left(s_{1} / s_{2}=0,46,0,92\right.$ и 1,83$)$, поверхности труб которых отличались шагом винтовой линии при $t$ ( 8 мм, 12 мм, 20 мм).

Анализ рис. 5 позволяет сделать вывод о том, что изменение шага винтовой линии поверхности трубы практически не влияет на сопротивление пучков. Полученные результаты сравнивались с расчетными соотношениями аэродинамического сопротивления шахматных гладкотрубних пучков, которые приведены в нормативном методе [9].

Рис. 5 свидетельствует, что увеличение продольного шага труб $s_{2}$ при постоянном поперечном шаге $s_{1}$ приводит к росту аэродинамического сопротивления, а увеличение $s_{1}$ при $s_{2}=$ const, напротив, приводит к уменьшению сопротивления. При этом наибольшее аэродинамическим сопротивлением у пучка с наибольшим продольным шагом $s_{2}=48 \mathrm{Mм}$, что соответствует $s_{1} / s_{2}=0,46$. Числа Эйлера для этого пучка в зависимости от чисел Рейнольдса изменяются от значения 0,23 до 0,17 . При этом аэродинамическое сопротивление пучка $s_{1} / s_{2}=0,46$ на $17 \%$ и $20 \%$ выше, чем для пучков с $s_{1} / s_{2}=0,92$ и $s_{1} / s_{2}=1,83$. Анализ приведенных на рис.5 данных также свидетельствует о том, что все исследованные пучки винтообразных труб имеют более высокое аэродинамическое сопротивление, чем соответствующие гладкотрубные пучки с теми же геометрическими характеристиками. Так пучок винтообразных труб с $s_{1} / s_{2}=1,83$ имеет на $46 \%$ большее аэродинамическое сопротивление по сравнению с пучком гладких труб, а пучки труб с $s_{1} / s_{2}=0,46$ и $s_{1} / s_{2}=0,92$ на $14 \%$ и на $5 \%$ соответственно. 


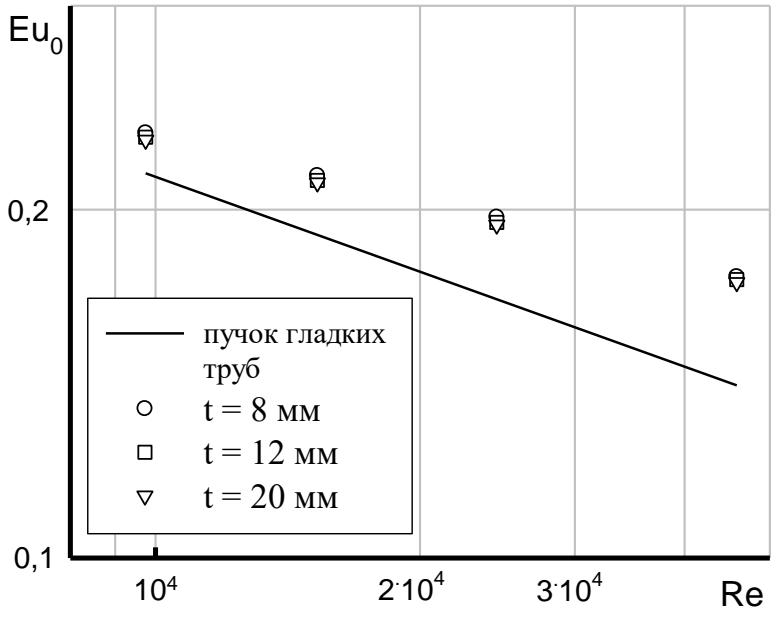

a)

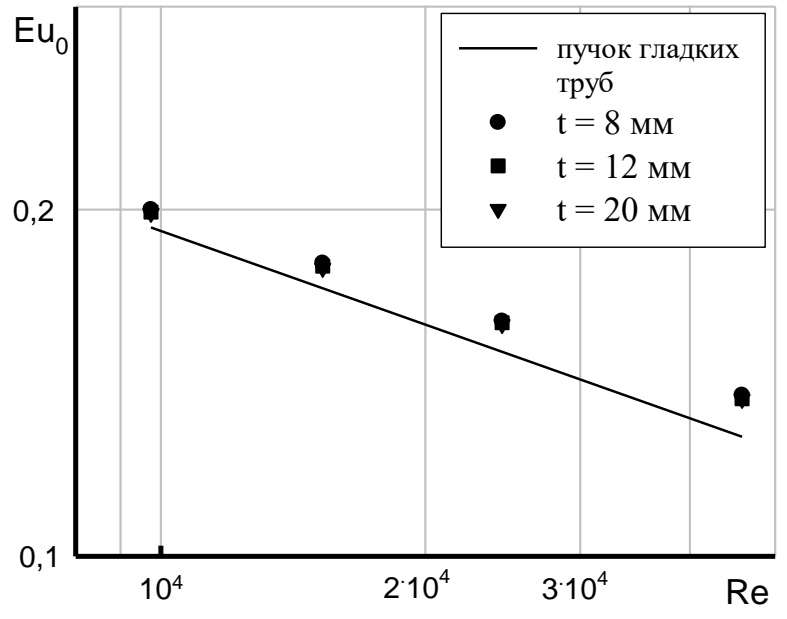

б)

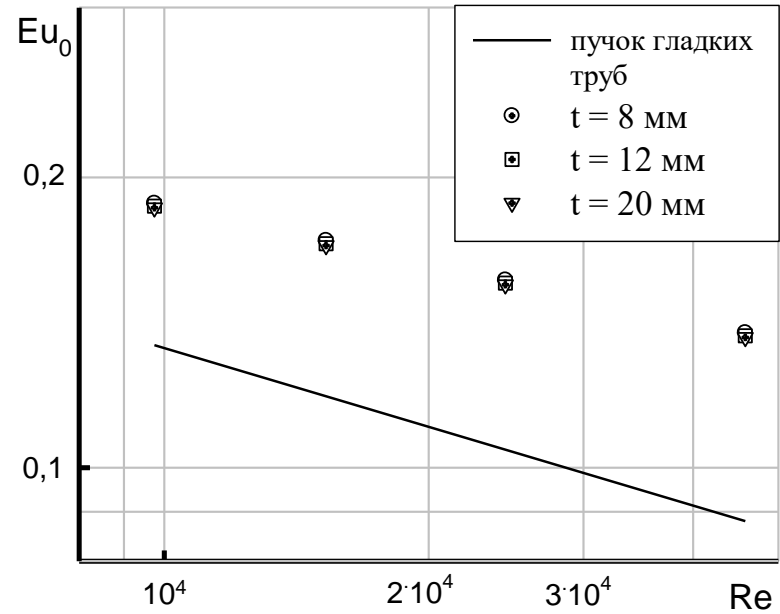

B)

Рисунок 5 - Зависимость $\mathrm{Eu}_{0}=f\left(\operatorname{Re}_{D}\right)$ для пучков винтообразных и гладких труб при $s_{1} / s_{2}=0,46$ (a), $s_{1} / s_{2}=0,92$ (б) и $s_{1} / s_{2}=1,83$ (в).

Пучки винтообразных труб с $s_{1} / s_{2}=22 / 24=0,92$ и $s_{1} / s_{2}=44 / 24=1,83$ имеют близкие значения аэродинамического сопротивления, отличающиеся не более чем на $10 \%$.

С учетом данных по теплообмену [13] и рекомендаций относительно требований компактности теплообменного аппарата, желательно использовать винтообразные трубы с шагом винтовой линии $t$ равным 8 мм при высоте выступов-впадин 2,5 мм. Трубы следует располагать в шахматном порядке с поперечным $s_{1}$ и продольным $s_{2}$ шагами 22 мм и 24 мм соответственно.

Обобщения данные из аэродинамического сопротивления при омывании потоком поверхности винтообразных труб

Анализ приведенных выше данных свидетельствует, что при поперечном омывании пучка труб зависимость аэродинамического сопротивления от режимных параметров потока $\mathrm{Eu}=f\left(\mathrm{RE}_{D}\right)$ можно обобщить степенной зависимостью вида

$$
\mathrm{Eu}=C_{s} \cdot \operatorname{Re}_{D}^{-n}
$$

Для получения расчетного соотношения, необходимо определить ряд параметров, которые влияют на аэродинамическое сопротивление шахматных пучков винтообразных труб. Коэффициенты $C_{s}$ и $n$ в формуле (3) являются функциями шаговых характеристик пучка и геометрических параметров труб. Учитывая существующий в литературе $[4,10,11]$ опыт обобщения результатов исследования аэродинамического сопротивления различных теплообменных поверхностей наиболее достоверным параметром, который учитывает форму пучка и геометрические параметры труб является параметр приведенной длины - H/F. Однако, проведенный анализ полученных данных показал, что параметр $H / F$ 
ISSN 1813-5420 (Print). Енергетика: економіка, технологіï, екологія. 2018. № 1

практически не влияет на аэродинамическое сопротивление, что связано на наш взгляд с тем фактом, что значения $H / F$ для исследованных пучков винтообразных труб незначительно отличаются друг от друга.

Для нахождения расчетной зависимости для аэродинамического сопротивления пучков труб согласно рис.5, определены значения коэффициентов $C_{s}^{\prime}$ и $n$, приведенные в таблицах 1-3.

Таблица 1 - Зависимость $\mathrm{Eu}=f(\operatorname{Re})$ при $s_{1} / s_{2}=22 / 48=0,46$

\begin{tabular}{|c|c|c|c|c|c|c|}
\hline$\underbrace{\mathrm{Re}}_{t, M M}$ & 9744 & 15282 & 24451 & 45846 & $C_{s}$ & $n$ \\
\hline 8 & 0,233 & 0,214 & 0,197 & 0,175 & 1,2635 & 0,184 \\
\hline 12 & 0,231 & 0,212 & 0,195 & 0,174 & 1,2315 & 0,1824 \\
\hline 20 & 0,2297 & 0,211 & 0,194 & 0,173 & 1,2274 & 0,1826 \\
\hline
\end{tabular}

Таблица 2.

Зависимость $\mathrm{Eu}=f(\mathrm{Re})$ при $s_{1} / s_{2}=22 / 24=0,92$

\begin{tabular}{|c|c|c|c|c|c|c|}
\hline$\overbrace{t, \mathrm{MM}}^{\mathrm{Re}}$ & 9744 & 15282 & 24451 & 45846 & $C_{s}$ & $n$ \\
\hline 8 & 0,2 & 0,1797 & 0,16 & 0,138 & 1,8154 & 0,24 \\
\hline 12 & 0,199 & 0,1786 & 0,1595 & 0,137 & 1,847 & 0,241 \\
\hline 20 & 0,1986 & 0,1779 & 0,159 & 0,1369 & 1,7986 & 0,24 \\
\hline
\end{tabular}

Зависимость $\mathrm{Eu}=f(\mathrm{Re})$ при $s_{1} / s_{2}=44 / 24=1,83$

Таблица 3.

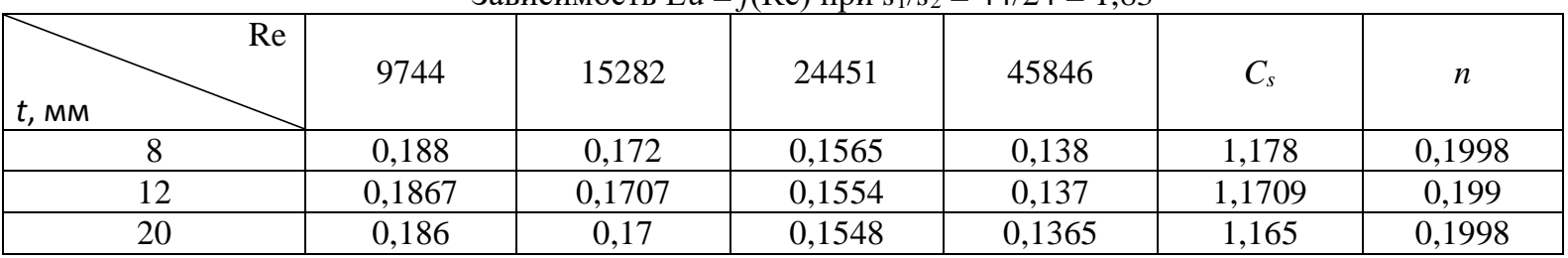

На основе представленных в таблицах 1-3 расчетных значений показателей степени и коэффициента $C_{s}$ в формуле подобия (3) получены графические (рис. 7) и аппроксимирующие зависимости для определения $n$ и $C_{s}$.

$$
\begin{gathered}
C_{s}=\frac{6,7}{\frac{2,1}{s_{1} / s_{2}}+2,1 \frac{s_{1}}{s_{2}}}, \\
n=\left(\frac{2,1}{s_{1} / s_{2}}+2,1 \frac{s_{1}}{s_{2}}\right)^{-1} .
\end{gathered}
$$

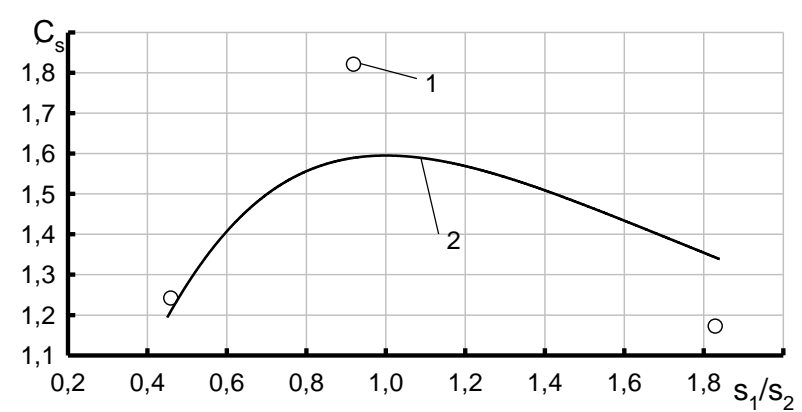

a)

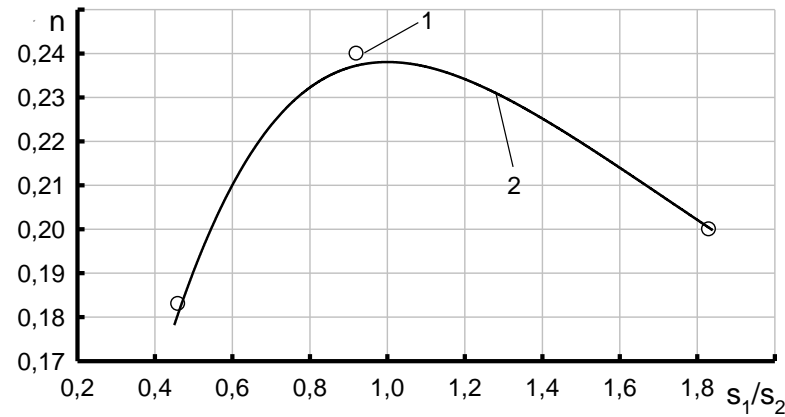

б)

1 - данные CFD-моделирования; 2 - расчет по зависимостям (4) и (5)

Рисунок 6 - Зависимости $C_{s}=f\left(s_{1} / s_{2}\right)$ (а) и $n=f\left(s_{1} / s_{2}\right)$ (б) для пучков винтообразных труб

С учетом соотношений (4)-(5), а также (3) формула для расчета аэродинамического сопротивления для трех шахматных пучков винтообразных труб с равноразвитой поверхностью имеет вид 


$$
E u=\left(\frac{6,7}{2,1 s_{1} / s_{2}+2,1 s_{1} / s_{2}}\right) \operatorname{Re}^{-\left(2,1 s_{1} / s_{2}+2,1 s_{1} / s_{2}\right)^{-1}} .
$$

Суммарная погрешность расчетных формул оценивалась прямым сопоставлением данных CFDмоделирования и рассчитанных по формулам (3)-(5) чисел Эйлера при фиксированных значениях чисел Рейнольдса $\mathrm{Re}_{\mathrm{D}}=10 \cdot 10^{3}$ и $\mathrm{Re}_{\mathrm{D}}=45 \cdot 10^{4}$. Разброс данных CFD-моделирования относительно расчетных зависимостей не превышает $\pm 6 \%$ для трех исследованных пучков винтообразных труб.

\section{Выводы}

Установлено, что в шахматных пучках винтообразных труб, как и в шахматных пучках гладких труб, увеличение $s_{2}$ при $s_{1}=$ const приводит к росту аэродинамического сопротивления, а увеличение $s_{1}$ при $s_{2}=$ const, напротив, приводит к уменьшению аэродинамического сопротивления.

Наибольшим аэродинамическим сопротивлением обладает пучок с шагом $s_{2}=48$ мм, что отвечает отношению $s_{1} / s_{2}=0,46$. При этом, сопротивление пучка из $s_{1} / s_{2}=0,46$ на $17 \%$ и $20 \%$ выше, чем для пучков из $s_{1} / s_{2}=0,92$ и 1,83 .

Исследованные пучки винтообразных труб имеют большее аэродинамическое сопротивление, чем гладкотрубные пучки с теми же параметрами: пучок винтообразных труб с $s_{1} / s_{2}=1,83$ на $46 \%$, а пучок труб с $s_{1} / s_{2}=0,46$ и $s_{1} / s_{2}=0,92$ на $14 \%$ и на $5 \%$ соответственно.

Пучки труб, с $s_{1} / s_{2}=22 / 24=0,92$ и $s_{1} / s_{2}=44 / 24=1,83$ имеют близкие значения аэродинамического сопротивления (данные отличаются не более чем на $10 \%$ ).

Изменение шага винтовой линии $t$ от 8 мм до 20 мм практически не влияет на аэродинамическое сопротивление шахматных пучков винтообразных труб.

C учетом рекомендаций относительно требований компактности теплообменного аппарата, желательно винтообразные трубы использовать с шагом винтовой линии $t$ равным 8 мм. Трубы следует располагать в шахматном порядке с поперечным $s_{1}$ и продольным $s_{2}$ шагами 22 и 24 мм соответственно.

В последующем целесообразно более детально исследовать влияние заходности винтовой линии на теплоаэродинамические характеристики пучков винтообразных труб.

\section{Список использованой литератури}

1.E.N. Pis'menniy. Ways for improving the tubular heaters used in gas turbine units// Thermal Engineering. - 2012. - Vol.59. - no. 6. - C.485-490.

2.Письменний Є.М. Теплообмін пучків труб з рівнорозвиненою поверхнею / С.М. Письменний, В.А. Рогачов, О.М. Терех, В.І. Коньшин, Д.С. Омельчук// Восточно-Европейский журнал передовых технологий. - 2013. - №1/8 (61). - С. 29 -33.

3.Письменний Є.М., Рева С.А., Терех О.М. Аеродинамічний опір пучків гвинтоподібних труб. Восточно-Европейский журнал передовых технологій. - 2013. - №6/8(66). - С. 31-35.

4.Письменный Е.Н. Обобщение данных по аэродинамическому сопротивлению пакетов винтообразных труб / Е.Н. Письменный, С.А. Рева, А.М. Терех, А.И. Руденко // Международный научноисследовательский журнал. - 2014. Ч.1. - № 5(24). - С. 103-106.

5.Калинин Э.К. Эффективные поверхности теплообмена / Э.К. Калинин, Г.А. Дрейцер, И.3. Копп, А.С. Мякочкин. - М.: Энергоатомиздат, $1998-400$ с.

6.Антуфьев В.М. Эффективность различных форм конвективных поверхностей нагрева / B.M. Антуфьев. - М.; Л.: Энергия, 1966. - 184 с.

7.Маковей В.О. Особливості профілювання одно- та трьохзахідних гвинтоподібних труб / В.О. Маковей, П.Ю. Проценко // Вестник Национального технического университета “ХПИ”. - 2013. №43(1016). - С.153-162.

8.Быстров Ю. А. Численное моделирование вихревой интенсификации теплообмена в пакетах труб / Ю. А. Быстров, С. А. Исаев, Н. А. Кудрявцев, А. И. Леонтьев. - С-Пб.: Судостроение, 2005. - 392 с.

9.Аэродинамический расчет котельных установок: нормативный метод. Изд. 3, под ред. С.И. Мочана. - Л.: Энергия, 1977. - 256 с.

10. Kays, W.M., Compact Heat Exchangers. Second edition / W.M. Kays, A.L. London. Mc Graw - Hill Book Company, New York, 1967. - 224 p.

11. Письменный Е.Н. Теплообмен и аэродинамика пакетов поперечно-оребренных труб / Е.Н. Письменный.. Киев: Альтерпрес, 2004. - 244 с.

12. Баранюк О.В. Теплообмін шахових пучків гвинтоподібних труб / О.В. Баранюк, В.А. Рогачов, Н.Ю. Андрусік // Енергетика: економіка, технології, екологія, 2017. - №6. - С.34-37. 
A. Baranyuk, Ph.D., senior lecturer ORCID 0000-0001-6008-6465

A. Terekh, Ph.D., senior Researcher ORCID 0000-0002-1320-8594

V. Yanushevskyy, master student, ORCID 0000-0003-0179-1433

National Technical University of Ukraine "Igor Sikorsky Kyiv Polytechnic Institute"

\section{CFD-MODELING OF AERODYNAMIC DRAG OF BUNDLES OF HELICAL TUBES}

With the help of CFD modeling, an investigation was made of the aerodynamic drag of staggered bundles of spiral-shaped tubes with an equal surface in the range of variation of Reynolds numbers from $9,5 \cdot 10^{3}$ to $45 \cdot 10^{3}$. All the bundles were formed from the three types of helical tubes investigated, which differ only in the pitch of the helical line $-t=8,12$ and $20 \mathrm{~mm}$. Other geometric parameters, namely the outer diameter $d=16 \mathrm{~mm}$, the depth of the protrusions of the single-thread helix $h=2,5 \mathrm{~mm}$ and the total tube length $l=500 \mathrm{~mm}$, did not change. Bundles models with step ratios between tubes $s_{1} / s_{2}=0,46,0,92$ and 1,83 are studied. It is shown that the aerodynamic drag of a bundle of helical tubes with $s_{1} / s_{2}=0,92$ is only $5 \%$ higher than a similar smooth-tube bundle. Calculated relationships are proposed for determining the aerodynamic drag of the studied staggered bundles of single-pass helical tubes with an equal surface. It is shown that the coefficient $C_{s}$ and the exponent $n$ at the Reynolds number in the similarity equation depend on the step characteristics of the bundles.

It is planned that application of helical tubes will allow to increase on (10-30)\% intensity of heat exchange at the moderate increase of aerodynamic resistance, due to what it is possible substantially to improve mass overall descriptions of heat-exchange devices. In the case of using of helical tubes in "gas-to-gas» heat exchangers makes it possible to increase the heat transfer rate with a moderate increase in aerodynamic drag, as a result of which it is possible to significantly improve the mass and dimensions characteristics of heat exchangers

Keywords: helical tubes, equaldeveloped surface, staggered package, aerodynamic drag, calculation

\section{References}

1.E.N. Pis'menniy. Ways for improving the tubular heaters used in gas turbine units// Thermal Engineering. - 2012. - Vol.59. - no. 6. - C.485-490.

2.Pis'mennyi E.N. Heat transfer of tube bundles with the equalincreased surfaces / E.N. Pis'mennyi, VA Rogachev, OM Terekh, V.I. Konshin, D.S. Omelchuk // Eastern European Journal of advanced technologies. 2013. - №1 / 8 (61). - S. 29 -33.

3.Pis'mennyi E.N. Aerodynamic drag of tube bundles with the equalincreased surfaces / E.N. Pis'mennyi, A.M. Terekh, V.A. Rogachov, A.I. Rudenko, S.A. Reva // Eastern European Journal of advanced technologies. 2013. - №6/8 (66). - P. 31 -35.

4.Pis'mennyi E.N., Reva S.A., Terekh A.M., Rudenko A.I. The generalized data of aerodynamic drag of the staggered bundles of screw-shaped tubes / E.N. Pis'mennyi, S.A. Reva, A.M. Terekh, A.I. Rudenko // International research journal. - 2014. - V.1. - N 5(24). P. 103-106.

5.Kalinin E.K. The effective surfaces of heat exchange / E.K. Kalinin, G.A. Dreitser, I.Z. Kopp, A.S. Myakochin. - Moscow.: Energoatomisdat, 1998. - 131 p.

6.Antufyev V.M. Efficiency of various forms of convective heating surfaces / V.M. Antufyev. - M-L .: Energia, $1966-184$ p.

7.Makovey V.O. Features of profiling of one- and three-western spiral tubes / B.O. Makovey, P.Yu. Protsenko // Announcer of the National technical university of "KHPI". - 2013. - №43(1016). - C.153-162.

8.Bystrov, Yu. A. Numerical simulation of the vortex intensification of heat transfer in stacks of tubes / Yu. A. Bystrov, S. A. Isayev, N. A. Kudryavtsev, A. I. Leont'yev. - St. Petersburg: Sudostroyeniye, 2005. - 392 p.

9.Aerodynamic calculation of boiler plants (standard method). Ed. 3, edited by S. Mochan, - Leningrad, USSR: Energy, 1977. - 256 p.

10. Kays W.M. Compact Heat Exchangers. Second edition / W.M. Kays, A.L. London - Mc Graw - Hill Book Company New York, 1967. - 224 p.

11. Pismennyi E. N. Heat Transfer and aerodynamic drag of tubes bundles with transversal finns / E. N. Pismennyi. - Kiev, Ukraine, Alterpress, 2004. - 244 p.

12. Baranyuk O.V. Heat exchange of chess beams of propeller tubes / O.V. Baranjuk, V.A. Rogachev, N.Yu. Andrushik // Energy: Economics, Technology, Ecology, 2017. - №4. - p.34-37. 
O.В. Баранюк, канд. техн. наук, доц., ст. викл., ORCID 0000-0001-6008-6465

O.M. Терех, канд. техн. наук, доц., с. н. с., ORCID 0000-0002-1320-8594

B.А. Янушевський, магістрант, ORCID 0000-0003-0179-1433

Національний технічний університет України «Київський політехнічний інститут імені Ігоря Сікорського»

\section{СFD-МОДЕЛЮВАННЯ АЕРОДИНАМІЧНОГО ОПОРУ ПУЧКІВ ГВИНТОПОДІБНИХ ТРУБ}

Засобами CFD-моделювання проведено дослідження аеродинамічного опору шахових пучків гвинтових труб з рівнорозвиненою поверхнею в діапазоні зміни чисел Рейнольдса від 9,5·10 Вивчено моделі пучків з відношеннями кроків між трубами $s_{1} / s_{2}=0,46,0,92$ i 1,83. Показано, шзо аеродинамічний опір пучка гвинтових труб з $s_{1} / s_{2}=0,92$ всього на $5 \%$ вище аналогічного гладкотрубного пучка. Запропоновано розрахункові співвідношення для визначення аеродинамічного опору досліджених шахових пучків однозахідних гвинтових труб з рівнорозвиненою поверхнею. Показано, шзо коефіцієнт $C_{s} i$ показник ступеня п при числі Рейнольдса в рівнянні подібності залежить від крокових характеристик пучків. Використання гвинтових труб в теплообмінниках типу «газ-газ» дозволяє збільшити інтенсивність теплообміну при помірному зростанні аеродинамічного опору, в результаті чого можна істотно поліпшити масогабаритні характеристики теплообмінних апаратів.

Ключові слюва: гвинтоподібна труба, рівнорозвинена поверхня, шаховий пучок, аеродинамічний опір, розрахунок.

Надійшла 12.02.2018

Received 12.02.2018 